\title{
Investigating the Effect of Acid Stress on Selected Mesophilic Micro-organisms implicated in Bioleaching
}

\author{
E. Ngoma and S.T.L. Harrison* \\ Centre for Bioprocess Engineering Research (CeBER), Department of Chemical Engineering, \\ University of Cape Town, Rondebosch 7701, South Africa. \\ *Corresponding author: Sue.Harrison@uct.ac.za
}

\begin{abstract}
During start-up of heap bioleaching, low grade ores are typically treated with acid for agglomeration and to combat the acid neutralising capacity of the gangue minerals. This may stress the bioleaching inocula, particularly upon inoculation during ore agglomeration. Acid addition for agglomeration varies across operations, ore types and their neutralising capacity, with limited information published on recommended concentrations. The initial $\mathrm{pH}$ in the agglomeration mix is typically below $\mathrm{pH} 1.0$ and may be as low as $\mathrm{pH} 0.5$.
\end{abstract}

This paper investigates the effect of acid stress in terms of initial acid concentration and exposure duration in submerged culture on mesophilic bacteria typically implicated in mineral sulphide bioleaching and critical for heap colonisation at start-up. Following acid stress, cultures were returned to standard operating conditions in batch stirred slurry reactors and their performance assessed in terms of mineral leach rates, ferrous oxidation and the rate of microbial growth. Increasing acid stress resulted in an increase in the lag period before onset of microbial growth and iron oxidation. Following adaptation, typical growth and ferrous iron oxidation rates were observed under low stress conditions while reduction in the rate and extent of microbial growth and ferrous iron oxidation persisted at extreme 
conditions. A reduction in yield (microbial cells produced per kg iron oxidised) was observed with increased acid concentration over comparative times. Microbial speciation analysis indicated a substantial decrease in the diversity of surviving bacterial species.

Keywords: Acid stress, agglomeration, mineral bioleaching, $\mathrm{pH}$ control, process optimisation

\section{Introduction}

Heap bioleaching is a hydrometallurgical process used to recover valuable metals from low grade ores containing minerals such as chalcocite $\left(\mathrm{Cu}_{2} \mathrm{~S}\right)$, covellite $(\mathrm{CuS})$ and, more recently, chalcopyrite $\left(\mathrm{CuFeS}_{2}\right)$ (Brierley 2008). Nickel, cobalt and zinc containing mineral sulphides are also amenable to bioleaching. Micro-organisms facilitate the dissolution of sulphide minerals by regenerating the ferric iron and protons responsible for mineral attack through oxidation of the ferrous iron and reduced sulphur species produced during mineral dissolution. This provides a continuous and potentially well-distributed source of leaching agent. Ideally, the rate of microbial regeneration of these leach agents ensures their plentiful supply such that mineral availability is rate limiting. However, effective microbial colonisation of heaps is required to achieve optimum microbial activity. Microbial colonisation is affected by the availability of naturally occurring micro-organisms, the effective introduction of micro-organisms, their adaptation to new conditions, such as humidity, acidity, aeration, energy and carbon source, their rapid attachment to the mineral and their metabolic activity (Africa et al., 2012; Chiume et at., 2012; Watling, 2006). 
During the heap preparation process the ore body is crushed to reduce particle size and increase cracks and fissures, thereby liberating the mineral of interest and exposing it to solution carrying the leach agent, thus increasing the dissolution of the metal (during the leaching step) and reducing extraction time. This, however, increases the amount of fine material. The fine materials affect percolation through the constructed heap, solid-liquid-gas contacting and the associated gas-liquid mass transfer. Poor percolation can lead to low metal extraction due to solution channelling or the development of impermeable (dead) zones within the heap (Kappes, 2005; Schlitt, 1992). Several heap leach operations are reported to have experienced problems associated with poor recovery due to percolation issues caused by low-grade complex ores, tailings and clayey deposits (Dhawan et al., 2013).

Agglomeration may be introduced subsequent to crushing as a pre-treatment to allow adhesion of the fines to the coarse material by addition of liquids such as the leaching solution and/or binders to produce strong and stable agglomerates in which fine particles coalesce onto larger rock particles via liquid bridges (Dhawan et al., 2012; Kodali et al., 2011; Bouffard, 2005). By increasing the uniformity of the resultant effective agglomerate size, agglomeration results in more uniformly permeable heaps, improving the percolation of solution through the ore.

The second role of crushed ore agglomeration is to provide an opportunity for the thorough application of the leaching solution prior to building the heap to initiate the leaching process itself (Dhawan et al., 2012; Bouffard, 2005; Purkiss and Anthony, 2004). Agglomeration solutions such as sulphuric acid are used for copper, nickel and uranium bearing ores and cyanide solutions used for gold and silver bearing ores, to improve the agglomeration process and facilitate the leaching of minerals (Bouffard, 2005). Acid agglomeration, used largely in the bioleaching of mineral sulphides, including copper-containing ores, also combats the acid neutralising capacity of the gangue mineral and prepares the ore for microbial attachment. 
Microbes experience stress when they are introduced into the operation due to changes in environmental conditions. This is especially pronounced if they are introduced during the agglomeration process. The effect of high acidity on microbial growth and leaching of mineral sulphides has been reported previously (Song et al., 2013, 2011; Tupikina et al., 2011, 2013; Plumb et al., 2008; Deveci et al., 2008). Plumb et al.(2008) studied the effect of the $\mathrm{pH}$ range 0.5 to 3.5 in a batch stirred tank reactor of microorganisms implicated in bioleaching and demonstrated varying $\mathrm{pH}$ optima for the six organisms studied (Acidithiobacillus thiooxidans, Acidithiobacillus caldus, Acidianus brierleyi, Leptospirillum ferriphilum, Sulfobacillus thermosulfidooxidans, Metallosphaera hakonensis) across the range $\mathrm{pH} 1.0$ to 2.5 . Their work is supported by the findings of Deveci et al. (2008) and Song et al (2013). While several organisms showed metabolic activity at $\mathrm{pH} 0.5$, in all cases it was reduced with respect to optimum $\mathrm{pH}$. In well-colonised heap leaching systems, the microbial oxidation rate exceeded the mineral leaching rate of low grade ore across the $\mathrm{pH}$ range 1.1 to 2.0 (Plumb et al., 2008). Negative effects were observed at $\mathrm{pH}$ less than 0.9 in moderately thermophilic and thermophilic systems, with growth and leaching seriously impaired at $\mathrm{pH}$ 0.7 (Tupikina et al. 2011, 2013).

While most bioleaching operations run at $\mathrm{pH}$ values in the range 1.2 to 2.5 (Plumb et al. 2008), the higher acidity levels used in industry during the agglomeration process are poorly documented and vary considerably from one operation to another. Further, little is reported in literature on the contribution of high acidity to microbial stress and its subsequent impact on the overall leaching performance.

In this paper, the effect of acidity and the duration of exposure on a mixed mesophilic culture comprised of organisms typically implicated in mineral bioleaching are investigated. The culture was subjected to increasing concentrations of sulphuric acid for one, three or 24 hours, prior to inoculation into a batch stirred tank reactor under typical operating conditions 
(initial $\mathrm{pH}$ of 1.4). On cultivation, the time of onset of microbial growth and ferrous iron oxidation and their rates were monitored. Performance was compared to that of a control test, not subjected to acid stress. In addition, using microbial species analysis conducted by qPCR, the relative tolerance of different microbial species to acid stress was considered.

\section{Experimental method and materials}

\subsection{Microbial cultures}

Microbial cultures used in this study were maintained as a mixed mesophilic stock culture containing $1 \%$ of Acidithiobacillus ferrooxidans (At. ferrooxidans), $5 \%$ of Acidiplasma cupricumulans (A. cupricumulans), 3 \% of Ferroplasma acidiphilum (F. acidiphilum), and predominantly $90 \%$ of Leptospirillum ferriphilum (L. ferriphilum), confirmed by qPCR. The micro-organisms were grown on a pyrite concentrate in a $1 \mathrm{~L}$ batch stirred tank reactor at $35^{\circ} \mathrm{C}$. The stock was sub-cultured on a weekly basis by removing $150 \mathrm{~mL}$ slurry and replacing it with $3.5 \mathrm{~g}$ of pyrite concentrate and $150 \mathrm{~mL}$ of Norris media (Norris et al., 1996), to allow the micro-organisms to remain active. The cell concentration was maintained at $1 \times 10^{9}$ to $4 \times 10^{9}$ cells $\mathrm{mL}^{-1}$.

\subsection{Mineral}

The pyrite concentrate provided by BHP Billiton (Randburg, South Africa) was used for energy source throughout the study. The milled concentrate was wet sieved to obtain a 38 $75 \mu \mathrm{m}$ size fraction. Size analysis was performed on the fraction using a Malvern Particle Size Analyser and $90 \%$ passed $53.18 \mu \mathrm{m}$ with $86 \%$ d50 and $31 \%$ d10. The composition of the concentrate was $41 \%$ sulphur and $50 \%$ iron. The relative density of the pyrite concentrate was $4.49 \mathrm{~kg} \mathrm{dm}^{-3}$ (measured). 


\subsection{Reactor set-up and experiments}

Identical glass jacketed stirred tank reactors (STR) of $0.18 \mathrm{~m}$ height, $0.10 \mathrm{~m}$ internal diameter, were used with a liquid working volume of $0.7 \mathrm{~L}$. The batch culture slurry contained media (Norris et al., 1996), a mixed mesophilic culture inoculum and $3 \%$ (w/v) pyrite concentrate. The operating temperature was maintained at $35^{\circ} \mathrm{C}$ by circulating heated water through the jacket. Aeration was achieved through a line sparger and controlled at $2 \mathrm{~L}$ compressed air per minute using a rotameter. Evaporation was minimised by passing a coolant maintained at $2{ }^{\circ} \mathrm{C}$ through the condensers. A set of four reactors were run at any given time: one control and three stress experiments.

For each experiment, $150 \mathrm{~mL}$ of inoculum containing $3 \times 10^{9}$ cells $\mathrm{mL}^{-1}$ was stressed at a specified acidity for the exposure time specified in Table 1. Following stress exposure, the inoculum was added to the bioleaching reactor at operational conditions for optimal leaching. The reactor contained $550 \mathrm{~mL}$ Norris media and $21 \mathrm{~g}(3 \% \mathrm{w} / \mathrm{v})$ of pyrite concentrate equilibrated at $35^{\circ} \mathrm{C}$. The reactor $\mathrm{pH}$ was adjusted to 1.40 using $\mathrm{Na}_{2} \mathrm{CO}_{3}$. The stressed culture was agitated at $550 \mathrm{rpm}$ (impeller tip speed of $1.64 \mathrm{~m} \mathrm{~s}^{-1}$ ) and aerated with $2 \mathrm{~L} \mathrm{~min}^{-1}$ compressed air.

Acid concentrations of $0.34,0.51$ and $0.68 \mathrm{M} \mathrm{H}_{2} \mathrm{SO}_{4}$ were used to stress the mixed mesophilic inoculum culture for 1,3 and 24 hours to simulate the effect of acid stress on microbial activity and growth during start-up of typical heap bioleaching operation. A control test was run concurrently using an unstressed inoculum. Table 1 summarises the experiments conducted and required additions for $\mathrm{pH}$ adjustment on inoculation. 
Table 1: Experiments conducted in sets of four, varying time exposure and the solution volume required to adjust the initial $\mathrm{pH}$

Test conditions

Acid concentration

[M]
Exposure time

[h]
Volume of pH adjusting agent upon addition to reactor post stress

$\begin{array}{lcccc}\text { Control } & 0 & 0 & 0 & 1.13\left(\mathrm{H}_{2} \mathrm{SO}_{4} 99 \%\right) \\ \mathbf{0 . 3 4} & 1 & 3 & 24 & 5.60\left(4 \mathrm{M} \mathrm{Na}_{2} \mathrm{CO}_{3}\right) \\ \mathbf{0 . 5 1} & 1 & 3 & 24 & 10.40\left(4 \mathrm{M} \mathrm{Na}_{2} \mathrm{CO}_{3}\right) \\ \mathbf{0 . 6 8} & 1 & 3 & 24 & 15.40\left(4 \mathrm{M} \mathrm{Na}_{2} \mathrm{CO}_{3}\right)\end{array}$

The experiments were monitored daily for $\mathrm{pH}$ using a $\mathrm{Ag} / \mathrm{AgCl}, 3 \mathrm{M} \mathrm{KCl}$ reference electrode attached to a Metrohm $704 \mathrm{pH}$ meter and for redox potential with a reference to a saturated $\mathrm{Ag} / \mathrm{AgCl}$ electrode using a Pt electrode attached to a Metrohm $827 \mathrm{pH}$ meter. The results are reported as Eh i.e. redox potential relative to the standard hydrogen electrode [SHE] calculated by adding a correction factor of $207 \mathrm{mV}$ to the value obtained for the $\mathrm{Ag} / \mathrm{AgCl}$ system at $25^{\circ} \mathrm{C}$ (Metrohm, South Africa). Microbial concentration was determined daily by direct count using a THOMA counting chamber under an Olympus CX-41 phase contrast microscope at $1500 \times$ magnification. Ferrous iron $\left(\mathrm{Fe}^{2+}\right)$ and total iron $\left(\mathrm{Fe}^{\text {tot }}\right)$ concentrations were determined using the colorimetric 1,10-phenanthroline method (Komadel and Stucki, 1988). The ferric iron $\left(\mathrm{Fe}^{3+}\right)$ concentration was calculated as the difference between $\mathrm{Fe}^{2+}$ and $\mathrm{Fe}^{\mathrm{tot}}$ concentrations.

The microbial speciation of the initial inoculum and that of the final cultures were compared to determine the effect of acid stress at the species level. The microbial composition of the samples collected was analysed by qPCR using 16s rRNA primers following extraction of gDNA from the cells (Tupikina et al, 2013). A 5-point serial dilution standard curve of the plasmid DNA ligated into pGEM-T Easy (Promega) was used for this protocol. The gDNA 
and a control were analysed in triplicate using the Rotor-Gene 6000 qPCR (Corbett Research) and SYBR ${ }^{\circledR}$ Fast Mastermix (KAPA Biosystems) with universal and species-specific primers shown in Table 2.

Table 2: PCR primers used to assay microbial composition in the inocula and cultivated stressed cultures (Tupikina et al., 2013).

\begin{tabular}{lll}
\hline Primer title & Microbial group/ species & Sequence (5' - 3') \\
\hline Universal primers & & \\
UniBactF335 & Universal bacteria & GAC TCC TAC GGG AGG CAG CA \\
UniBactR937 & Universal bacteria & TTG TGC GGG CCC CCG TCA AT \\
UniArchF343 & Universal archaea & ACG GGG IGC AIC AGG CG \\
UniArchR932 & Universal archaea & TGC TCC CCC GCC AAT TCC \\
\hline Archaeal primers & & \\
Ferro & F. acidiphilum & GAA GCT TAA CTC CAG AAA GTC TG \\
JTC3 & A. cupricumulans & AAG CCT AAC TTC AGA AGG CCT G \\
\hline Bacterial primers & & \\
ATT & At. thiooxidans. & GGG TGC TAA TAN CGC CTG CT \\
At.c & At. caldus & CGG ATC CGA ATA CGG TCT G \\
At.f & At. ferrooxidans & AGG TGG GTT CTA ATA CAA TCT GCT \\
At.f D2 & At. ferrooxidans strain D2 & CGG GTC CTA ATA CGA TCT GCT \\
L.ferri LH & L. ferriphilum strain LH & GGG GGC CTG AAT AAG GTC A \\
SG2/STO & S. thermosulfidooxidans & ACG AAG ACC GGC CCG GAA GG \\
SDO & S. disulfidooxidans & GAG AAT GCC TTG GAA ACT GCA A \\
\hline
\end{tabular}

Specific growth rates and the lag time preceding cell growth (calculated as the time at which the linear relationship between $\ln (\mathrm{X})$ and incubation time intercepted $\ln \left(\mathrm{X}_{0}\right)$ where $\mathrm{X}$ is the cell concentration at time $\mathrm{t}$ and $\mathrm{X}_{0}$ represented the cell concentration in the abiotic system) were estimated from the microbial cell count data. Leaching rates and the lag in the onset of leaching (calculated as the time at which the linear rate of iron release intercepted the baseline solubilised iron concentration) were estimated from the ferric iron concentration data collected. Intra-experiment reproducibility was determined using three identical inocula stressed with $0.51 \mathrm{M} \mathrm{H}_{2} \mathrm{SO}_{4}$ for 3 hours, re-suspended under identical optimal conditions and 
cultivated for 360 hours. Inter-experiment reproducibility was assessed by comparison of the control cultures from each set of experiments.

\section{Results and discussion}

\subsection{Reproducibility of experiment}

Both intra-experiment and inter-experiment reproducibility were analysed to provide a framework for appropriate data analysis across this study. The reproduced variation in measured microbial cell counts and calculated percentage iron released into solution within the same experiment are illustrated as a function of time in Figure 1.

The microbial lag time required for stress recovery following exposure to $0.51 \mathrm{M} \mathrm{H}_{2} \mathrm{SO}_{4}$ for $3 \mathrm{~h}$ was just over 93 hours. The average specific microbial growth rate across the three reactors was $0.011 \mathrm{~h}^{-1}$ with a relative error of $2.6 \%$. The $\mathrm{pH}$ measured (data not shown) followed a classic leaching profile with a sharp drop in $\mathrm{pH}$ representing acidification of the medium due to oxidation of the sulphur present in the pyrite to form sulphuric acid. The reproducibility of the $\mathrm{pH}$ data was demonstrated by a relative error between $0.44 \%$ and 1.93 $\%$. At the beginning of the exponential phase, the average Eh of $696 \mathrm{mV}$ increased to 713 $\mathrm{mV}$ at 70 hours for the first two reactors and to a high of $850 \mathrm{mV}$ for the third reactor. The ferric to ferrous iron ratio during that time was recorded to be 1/0.37 for Reactors 1 and 2 and 1/0.007 for Reactor 3. The average standard error in Eh was $1.56 \%$ across most of the profile, with a higher standard error of $14.3 \%$ recorded as the lag period (determined by iron oxidation) ended at $70 \mathrm{~h}$. Thereafter the Eh across the three reactors increased to the same value and maintained this value with a standard error of $0.77 \%$. The onset of microbial activity was slightly earlier in Reactor 3 . 

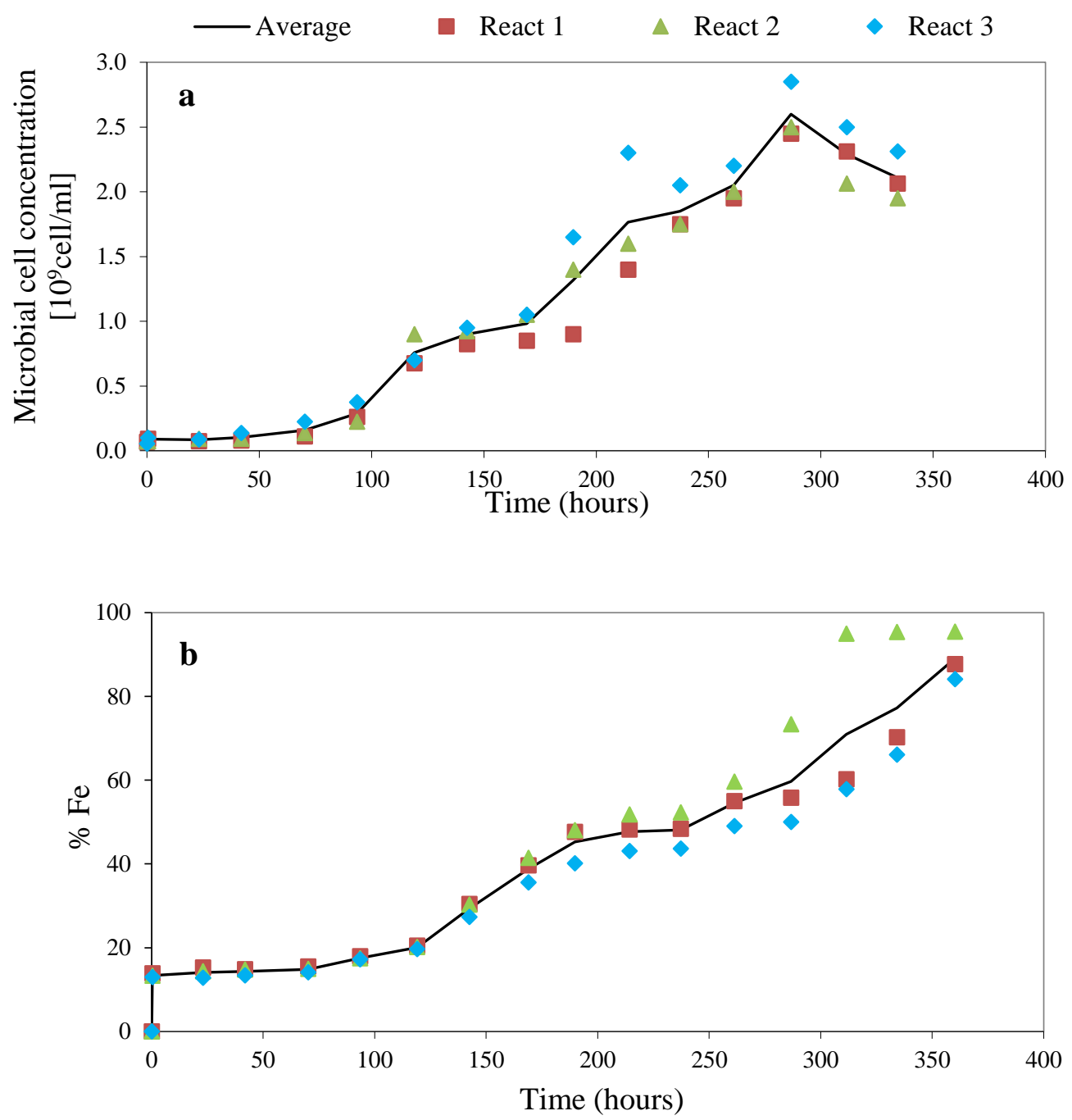

Figure 1. Trend in (a) microbial cell counts and (b) percentage iron released during the leaching experiment following acid stress at $0.51 \mathrm{M} \mathrm{H}_{2} \mathrm{SO}_{4}$ for 3 hours, with triplicate experiments (shaded symbols) and the average values (straight line) to demonstrate intra-experiment reproducibility.

The initial increase in iron concentration observed in the sample taken at 24 minutes resulted from chemical leaching of pyrite by ferric iron present in the inocula. The subsequent iron release lagged for a period of nearly $119 \mathrm{~h}$ before gradually increasing, indicating the recovery of stressed microbes, through the increased microbial oxidation of ferrous iron and subsequent ferric leaching of the pyrite. The average volumetric leach rate across the three reactors was calculated to be $0.028 \pm 0.002 \mathrm{~kg}$ iron $\mathrm{m}^{-3} \mathrm{~h}^{-1}$. The calculated percentage iron released, either into solution or precipitated, in the initial phases of leaching was consistent in the three reactors, with the standard deviation of $\pm 2.1 \%$ determined over the first $287 \mathrm{~h}$. 
Inter-experiment reproducibility was assessed by comparing the control cultures for the stress experiments conducted at various time exposures. The reproducibility of the microbial cell count and iron released across the three reactors is shown in Figure 2.

The relative error in $\mathrm{pH}$ observed across experiments lay between $2.03 \%$ and $10 \%$ with an average of $4.60 \%$ and a high of $10 \%$ recorded at $70 \mathrm{~h}$. The Eh data recorded depicted a trend similar to the $\mathrm{pH}$. The average relative error calculated was $2.5 \%$, with the highest error of $12 \%$ recorded at $45 \mathrm{~h}$ at which point microbial activity and leaching were initiated following the lag period. The lag period was recorded to be less than $40 \mathrm{~h}$ post inoculation for all three control cultures. Directly following the lag phase, the increase in microbial concentration was consistent over the next $80 \mathrm{~h}$ with a relative error between 4 and $15 \%$. Control culture 3 took longer to achieve the highest microbial count, resulting in a relative error as high as $30 \%$ at time 210 h. Similarly good reproducibility was shown for the percentage iron undergoing dissolution across the experiment with higher deviations over the final 60 hours. The microbial growth rates varied between 0.035 to $0.056 \mathrm{~h}^{-1}$ across the three control reactors, with an average of $0.043 \mathrm{~h}^{-1}$ and relative error of $15.1 \%$.

The analysis of these reproducibility experiments has demonstrated an acceptable marginal error within each experiment. The largest variations in data across experiments resulted from small changes in the onset of growth and microbial activity, resulting from minor variations in inoculum conditions. A positive control has been included in each experiment to address inter-experiment variability, allowing acceptable statistical assessement of this study. 

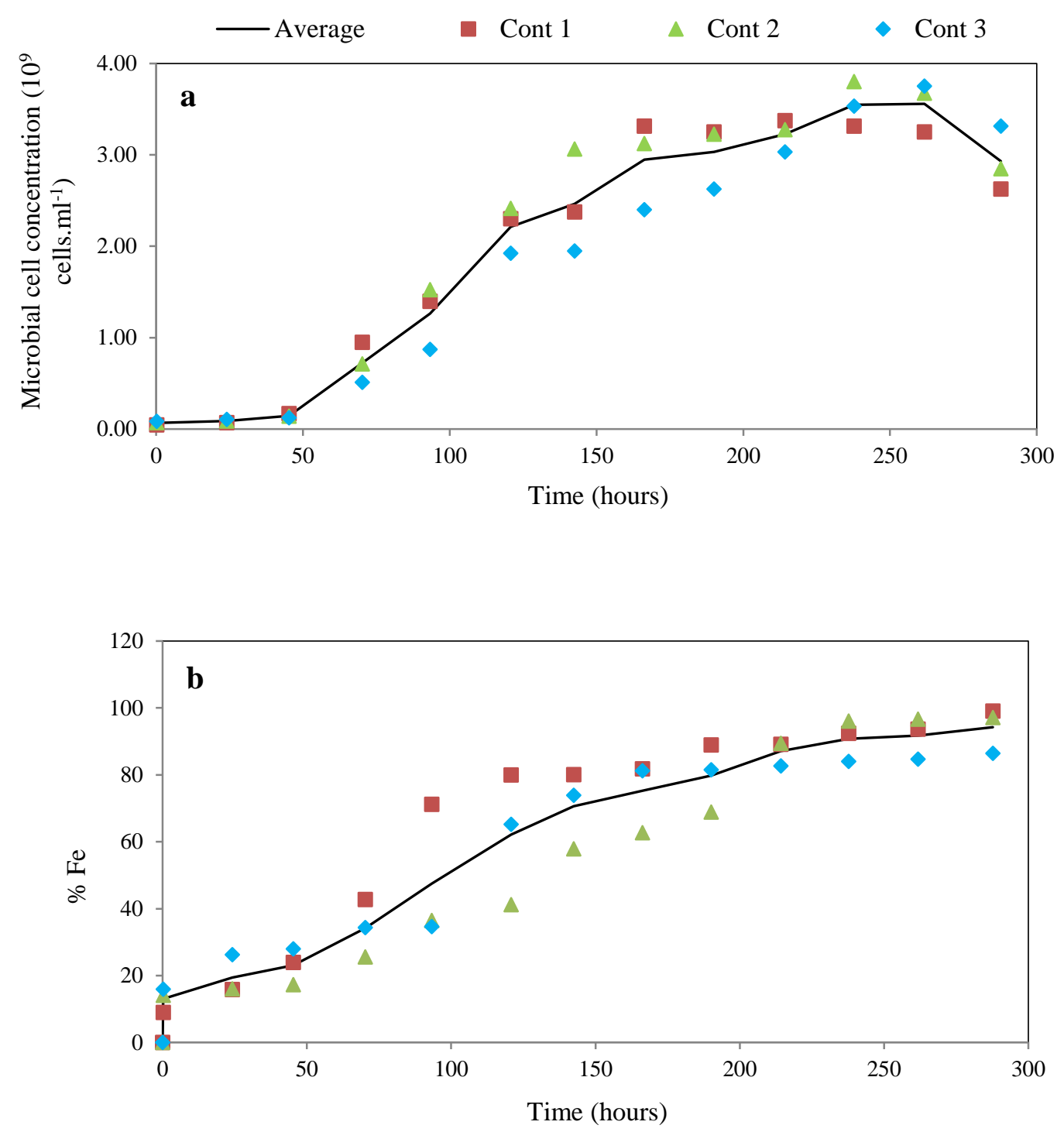

Figure 2. Trend in (a) microbial cell counts and (b) percentage iron released from the control cultures of the experiments for 1 hour, 3 hours and 24 hours exposure time. Triplicate control experiments (shaded symbols) and the average values (straight line) demonstrate inter-experiment reproducibility.

\subsection{Effect of Acid Stress}

In a previous study, Nemati and Harrison (2000) found the planktonic microbial concentration to be an appropriate measure of the trends in the biomass phase within multiphase bioreactor. The planktonic cell concentrations are given as a function of time following acid stress for $0,1,3$ and 24 hours in Figure 3. A short initial lag phase in microbial growth was observed for the control cultures, varying between $30 \mathrm{~h}$ and $50 \mathrm{~h}$. 
Thereafter the exponential phase was initiated and lasted from 30 to $161 \mathrm{~h}$, continuing through late exponential phase to $261 \mathrm{~h}$ where the highest planktonic cell numbers reached were $3.38 \times 10^{9}$ cells $\mathrm{mL}^{-1}, 3.80 \times 10^{9}$ cells $\mathrm{mL}^{-1}$ and $3.75 \times 10^{9}$ cells $\mathrm{mL}^{-1}$ respectively. Cultures stressed with $0.34 \mathrm{M}, 0.51 \mathrm{M}$ and $0.68 \mathrm{M}$ sulphuric acid demonstrated by the increase in lag period with increasing exposure time and acid concentration. The lag period increased to between $73 \mathrm{~h}$ to $259 \mathrm{~h}$ following acid stress. The achievement of highest planktonic cell numbers was similarly delayed. The cultures stressed with $0.34 \mathrm{M}, 0.51 \mathrm{M}$ and $0.68 \mathrm{M}$ acid achieved maximum planktonic cell numbers at times between $241 \mathrm{~h}$ and 406 $\mathrm{h}$ when exposed to these stresses for 1, 3 and 24 hours. Thereafter the planktonic cell number decreased indicating the death phase due to nutrient or energy limitation. 

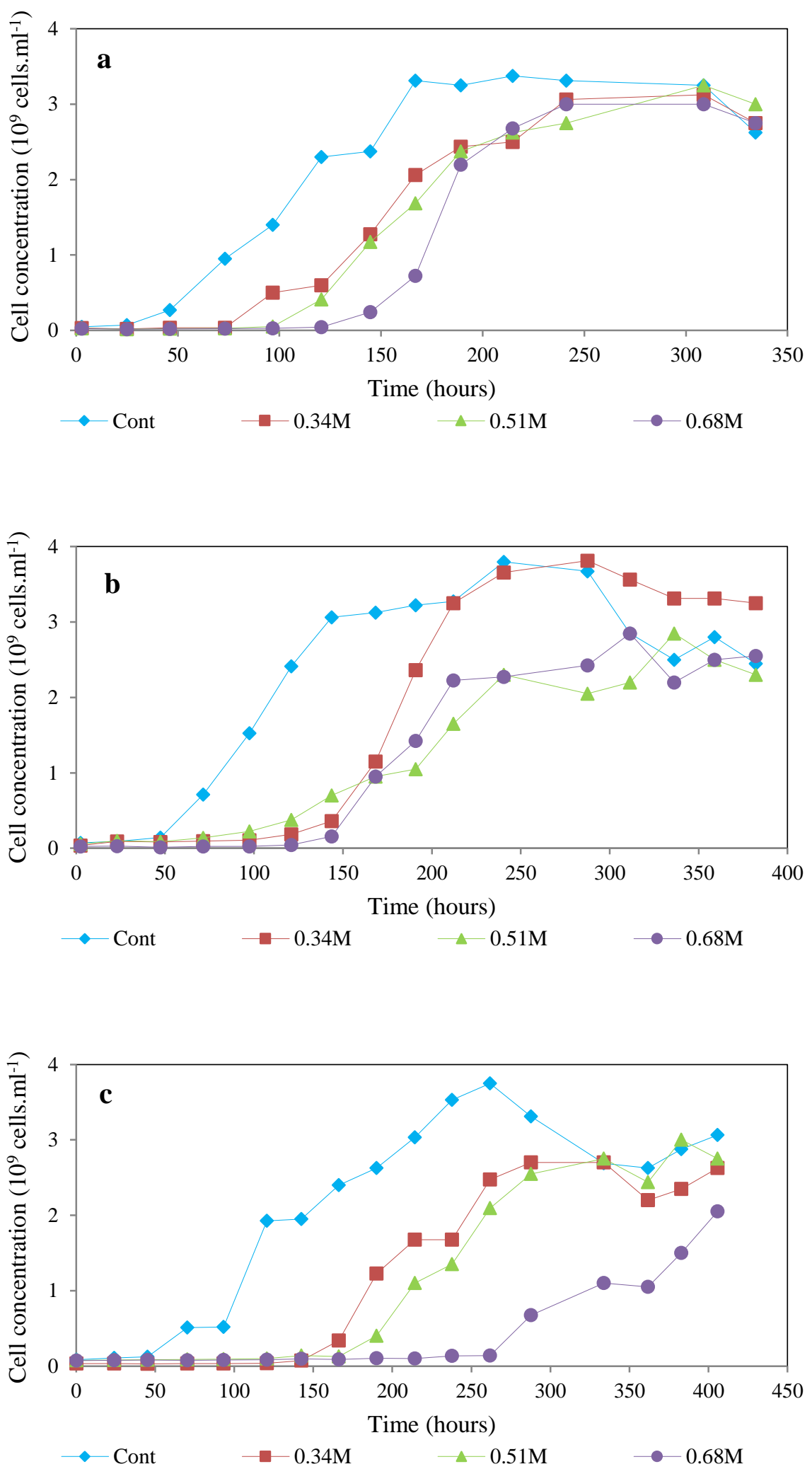

Figure 3. Planktonic microbial cell concentration profiles following exposure to acid stresses over (a) 1 hour, (b) 3 hours and (c) 24 hours in $3 \%$ pyrite slurry as a function of time. 
Table 3 summarises the calculated maximum specific growth rates, the lag period prior to growth, the maximum cell concentrations, the time of maximum cell concentration and the yield in terms of the microbial cells produced per $\mathrm{kg}$ iron oxidised for the controls and cultures following exposure to acid stress. The yield was calculated across the time interval of the experiment from inoculation until the control reactor reached maximum cell concentration. The specific growth rates following acid exposure of 1 and 3 hours changed relatively little after the extended lag period ( 0.9 to 1.1 fold the control value). However, with exposure to acid stress for 24 hours, the specific growth rates following the lag period had increased after exposure to a low acid stress (1.7 fold the control). At the highest acid stress of $0.68 \mathrm{M} \mathrm{H}_{2} \mathrm{SO}_{4}$, recovery was not observed and the highest specific growth rate recorded was 0.5 fold that of the control. Most notably the lag period prior to the onset of microbial growth increased as a function of increasing exposure to stress, both in terms of increasing acid exposure time and acid concentration.

The effect was most pronounced in the 24 hour system where the increase in lag time was as high as 5.1 fold that of the control. This increase in lag time has been demonstrated previously in response to process stress mediated through solids loading in leaching systems (Nemati and Harrison, 2000). 
Table 3: Microbial cell performances following recovery from acid stress.

\begin{tabular}{|c|c|c|c|c|c|c|}
\hline $\begin{array}{l}\text { Exposure } \\
\text { Time }\end{array}$ & $\begin{array}{c}\text { Acid } \\
\text { concentration }\end{array}$ & $\begin{array}{c}\text { Max } \\
\text { Specific } \\
\text { Growth } \\
\text { Rate }\end{array}$ & $\begin{array}{c}\text { Lag } \\
\text { phase }\end{array}$ & $\begin{array}{c}\text { Max cell } \\
\text { concentration }\end{array}$ & $\begin{array}{c}\text { Time max } \\
\text { cell achieved }\end{array}$ & $\begin{array}{l}\text { Comparative } \\
\text { Yield } \mathrm{x} / \mathrm{Fe}\end{array}$ \\
\hline [h] & {$[\mathbf{M}]$} & {$\left[\mathbf{h}^{-1}\right]$} & [h] & {$\left[10^{9}\right.$ cell $\left.\mathrm{mL}^{-1}\right]$} & [h] & $\begin{array}{c}{\left[10^{14} \text { cells kg- }\right.} \\
\left.{ }^{1} \mathrm{Fe}\right]\end{array}$ \\
\hline \multirow{4}{*}{1} & Control & 0.056 & $30.6 \pm 5.9$ & 3.38 & 167 & 3.67 \\
\hline & 0.34 & 0.050 & $73.2 \pm 1.9$ & 3.06 & 241 & 2.75 \\
\hline & 0.51 & 0.064 & $94.2 \pm 2.9$ & 3.25 & 309 & 2.48 \\
\hline & 0.68 & 0.062 & $\begin{array}{c}143.3 \pm \\
1.5\end{array}$ & 3.00 & 309 & 1.88 \\
\hline \multirow{4}{*}{3} & Control & 0.040 & $43.6 \pm 4.7$ & 3.80 & 212 & 4.13 \\
\hline & 0.34 & 0.038 & $\begin{array}{c}119.5 \pm \\
3.2\end{array}$ & 2.48 & 288 & 2.01 \\
\hline & 0.51 & 0.022 & $\begin{array}{c}120.8 \pm \\
2.1\end{array}$ & 2.85 & 336 & 1.94 \\
\hline & 0.68 & 0.040 & $\begin{array}{c}144.8 \pm \\
2.1\end{array}$ & 2.85 & 312 & 0.25 \\
\hline \multirow{4}{*}{24} & Control & 0.035 & $50.7 \pm 4.2$ & 3.75 & 261 & 3.24 \\
\hline & 0.34 & 0.059 & $\begin{array}{c}167.9 \pm \\
2.3\end{array}$ & 3.56 & 288 & 3.14 \\
\hline & 0.51 & 0.045 & $\begin{array}{c}191.5 \pm \\
2.4\end{array}$ & 2.44 & 383 & 2.15 \\
\hline & 0.68 & 0.019 & $\begin{array}{c}259.4 \pm \\
2.6\end{array}$ & 1.50 & 406 & 0.39 \\
\hline
\end{tabular}

Note: The fits all had an $\mathrm{R}^{2}$ value greater than 0.96 and the reported yields were calculated at the end of the Control culture exponential phase.

Under all levels of exposure to acid stress, the calculated comparative yields in terms of microbial cells produced per $\mathrm{kg}$ iron, were reduced relative to the control, with the most stressed cultures showing the lowest biomass yield. However, upon reaching the maximum cell concentration in the experiment following recovery, the final yield of the stressed 
cultures increased to those of the control except under the most extreme stress condition. As such, the culture stressed under $0.51 \mathrm{M}$ acid for 3 hours yielded $1.94 \times 10^{14}$ cells kg-1 $\mathrm{Fe}$ at the time point corresponding to maximum cell concentration in the control reactor. It reached a higher final yield of $4.67 \times 10^{14}$ cells kg-1 $\mathrm{Fe}$ by the time the maximum cell concentration of $3.30 \times 10^{9}$ cells $\mathrm{mL}^{-1}$ was reached in the stressed culture. Similarly the culture stressed with $0.68 \mathrm{M}$ acid for 1 hour only yielded $1.88 \times 10^{14}$ cells $\mathrm{kg}^{-1} \mathrm{Fe}$ at the time point corresponding to maximum cell concentration in the control, but reached a higher final yield of $3.15 \times 10^{14}$ cells $\mathrm{kg}^{-1} \mathrm{Fe}$ when the stressed culture had achieved its maximum cell concentration of $3.50 \times$ $10^{9}$ cells $\mathrm{mL}^{-1}$.

The total iron concentration released, accounting for iron in solution as well as precipitated iron, is presented in Figure 4, as a function of time for the controls and acid stressed cultures. The Eh in the control reactors in which the inoculum was not subjected to acid stress increased from an initial $500-540 \mathrm{mV}$ to a high of $790-794 \mathrm{mV}$ within $100-121$ hours, indicating that the micro-organisms were active and efficient in converting $\mathrm{Fe}^{2+}$ to $\mathrm{Fe}^{3+}$ directly following their inoculation. For the acid-stressed cultures, an initial decrease in Eh from $734 \mathrm{mV}$ to a low of approximately $670 \mathrm{mV}$ was observed. This is indicative of the lag period required by the micro-organisms to recover from the acid stress, during which the residual $\mathrm{Fe}^{3+}$ was converted to $\mathrm{Fe}^{2+}$ through pyrite dissolution.

The average extent of mineral solubilisation in the control cultures was $96 \%$, achieved between 120 and $166 \mathrm{~h}$ post inoculation. While the control cultures required between 40 and $55 \mathrm{~h}$ to initiate the oxidation of $\mathrm{Fe}^{2+}$ to $\mathrm{Fe}^{3+}$, the cultures stressed with acid displayed increasing lag times before the microbial oxidation and associated mineral leaching could be initiated. This increase was influenced by both the acid concentration and the time of exposure. The $0.34 \mathrm{M}$ acid stressed cultures required between 90 and $168 \mathrm{~h}$ to initiate the microbial oxidation and associated leaching. Equally, between 103 and $194 \mathrm{~h}$ and between 
137 and $260 \mathrm{~h}$ were required for the $0.51 \mathrm{M}$ and the $0.68 \mathrm{M}$ acid stressed cultures respectively, to initiate $\mathrm{Fe}^{2+}$ oxidation.
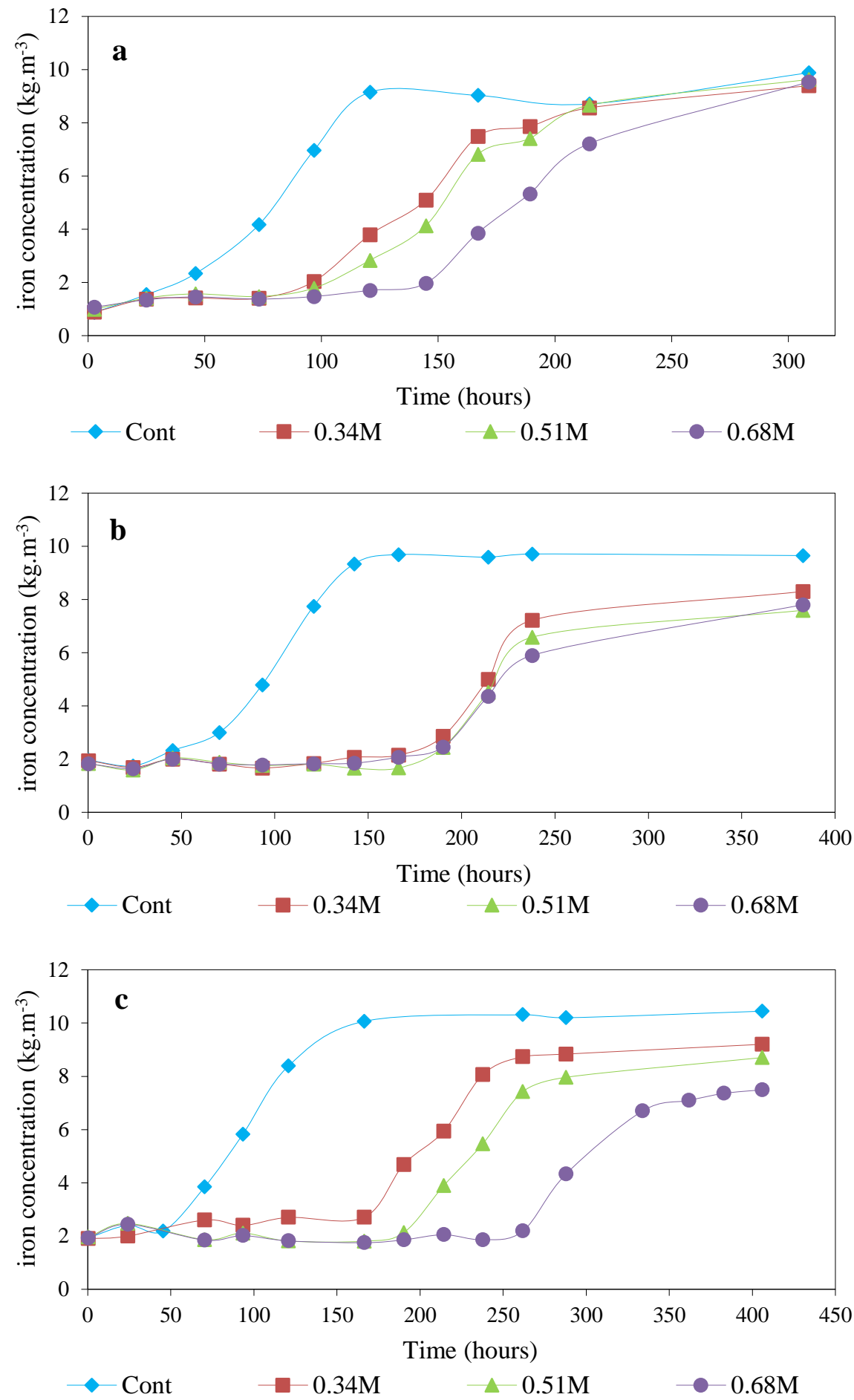

Figure 4. Total iron released (both into solution and precipitated) of the controls and cultures following exposure to acid stresses over (a) 1 hour, (b) 3 hours and (c) 24 hours in a 3\% pyrite slurry as a function of time. 
Table 4 summarises the calculated maximum leach rates, the lag period preceding leaching of iron and the extent of solubilisation of iron in the control cultures and the cultures exposed to acid stress. The extent of solubilisation for the stressed cultures was reduced to less than 90 $\%$ despite longer cultivation than the control culture. The time needed to achieve the highest extent of pyrite solubilisation also increased with increased acid concentration and exposure time. The $0.34 \mathrm{M}$ stressed cultures achieved a mineral solubilisation of $88 \%, 79 \%$ and $80 \%$ when left exposed to the stress for 1, 3 and 24 hours respectively. Similarly, the mineral solubilisation of $88 \%, 76 \%$ and $77 \%$ was recorded for the $0.51 \mathrm{M}$ stressed cultures, while reduced extents of leaching of $82 \%, 77 \%$ and $68 \%$ were recorded for the $0.68 \mathrm{M}$ stressed cultures following acid exposure for 1, 3 and 24 hours.

Following the recovery or lag period, the microbial $\mathrm{Fe}^{2+}$ oxidation rate and associated leaching performance did not change significantly. The lowest iron solubilisation rate was $0.061 \mathrm{~kg}$ iron $\mathrm{m}^{-3} \mathrm{~h}^{-1}$ when the culture was most stressed $\left(0.68 \mathrm{M} \mathrm{H}_{2} \mathrm{SO}_{4}, 24\right.$ hours $)$ compared to $0.075 \mathrm{~kg}$ iron $\mathrm{m}^{-3} \mathrm{~h}^{-1}$ when the culture was exposed to the lowest stress condition $(0.34 \mathrm{M}$ $\mathrm{H}_{2} \mathrm{SO}_{4}, 1$ hour) and $0.090-0.093 \mathrm{~kg}$ iron $\mathrm{m}^{-3} \mathrm{~h}^{-1}$ for the controls. For all conditions except two, the iron release rate following acid stress was reduced to between 77 and $82 \%$ of that obtained in the absence of the acid stress; however its onset was delayed by 2 to 3 fold. Under the most extreme stress, the rate decreased to $68 \%$ of the control following an increase in lag time of 4.8 fold. A leach rate of $0.084 \mathrm{~kg}$ iron $\mathrm{m}^{-3} \mathrm{~h}^{-1}$ was observed when the culture was stressed with $0.68 \mathrm{M}$ acid for 3 hours. This represented $93 \%$ of the rate observed for the control, following a lag time increase of 3.2 fold. The extent of solubilisation decreased from between 94 and $97 \%$ in the controls, to between 77 and $88 \%$ under all stress conditions except the most extreme, where $68 \%$ solubilisation resulted. While the 
performance did recover following the acid stress, the duration of the leaching phase increased by 2 to 3 fold.

Table 4: Maximum calculated leaching performances and extent of pyrite solubilisation following recovery from acid stress subjected for one, three and twenty four hours.

\begin{tabular}{|c|c|c|c|c|c|}
\hline Exposure time & $\begin{array}{c}\text { Acid } \\
\text { concentration } \\
{[\mathrm{M}]}\end{array}$ & $\begin{array}{c}\text { Max leach } \\
\text { rate } \\
{\left[\mathrm{kg} \mathrm{Fe} \mathrm{m}^{-3} \mathbf{h}^{-1}\right]}\end{array}$ & $\begin{array}{c}\text { Lag phase Fe } \\
\text { oxidation } \\
{[\mathrm{h}]}\end{array}$ & $\begin{array}{c}\begin{array}{c}\text { Extent of } \\
\text { solubilisation }\end{array} \\
{[\%]}\end{array}$ & $\begin{array}{c}\text { Time to complete } \\
\text { leaching } \\
{[\mathrm{h}]}\end{array}$ \\
\hline \multirow{4}{*}{1} & Control & 0.093 & $40.1 \pm 1.6$ & 94 & 120 \\
\hline & $0.34 \mathrm{M}$ & 0.075 & $91.4 \pm 2.0$ & 88 & 214 \\
\hline & $0.51 \mathrm{M}$ & 0.072 & $103.3 \pm 2.1$ & 88 & 214 \\
\hline & $0.68 \mathrm{M}$ & 0.074 & $137.7 \pm 2.0$ & 82 & 214 \\
\hline \multirow{4}{*}{3} & Control & 0.090 & $57.8 \pm 2.0$ & 97 & 142 \\
\hline & $0.34 \mathrm{M}$ & 0.073 & $167.8 \pm 2.4$ & 79 & 382 \\
\hline & $0.51 \mathrm{M}$ & 0.071 & $173.6 \pm 2.5$ & 76 & 382 \\
\hline & $0.68 \mathrm{M}$ & 0.084 & $182.8 \pm 2.1$ & 77 & 382 \\
\hline \multirow{4}{*}{24} & Control & 0.090 & $53.7 \pm 2.5$ & 97 & 166 \\
\hline & $0.34 \mathrm{M}$ & 0.071 & $158.7 \pm 3.2$ & 80 & 405 \\
\hline & $0.51 \mathrm{M}$ & 0.074 & $193.8 \pm 3.1$ & 77 & 405 \\
\hline & $0.68 \mathrm{M}$ & 0.061 & $260.1 \pm 3.7$ & 68 & 405 \\
\hline
\end{tabular}

Note: $\quad$ The fits all had an $\mathrm{R}^{2}$ value greater than 0.95 .

The general observation of this work has shown little effect on the maximum specific growth rate following the time needed for recovery by the stressed micro-organisms under all, except the most extreme, stress conditions. The iron leaching rate was decreased by a factor of 0.77 to 0.82 in all cases except the most extreme, following recovery. These recovery times were observed for both the growth of microbes and for the initiation of the ferrous oxidation. The lag time for the onset of microbial growth and ferrous oxidation were assessed in terms of 
time exposure and acid concentrations. The lag times were increased between 2.4 to 4.7 fold for microbial growth and 2.3 to 3.4 fold for ferrous oxidation following acid stress for one hour. Following the three hour stress, a 2.7 to 3.3 fold increase in lag time of microbial growth and 2.9 to 3.2 fold increase for ferrous oxidation were observed relative to the control. Similarly increases of 3.3 to 5.1 fold (microbial growth) and 3.0 to 4.8 fold (ferrous oxidation) were observed following the 24 hour stress. Equally the lag phases, when assessed in terms of acid concentrations and compared to the control cultures, are increased between 2.4 to 3.3 fold (microbial growth) and 2.3 to 3.0 fold (ferrous oxidation) when stressed with $0.34 \mathrm{M}$ acid; 3.1 to 3.8 fold (microbial growth) and 2.6 to 3.6 fold (ferrous oxidation) when stressed with $0.51 \mathrm{M}$ acid and 4.7 to 5.1 fold (microbial growth) and 3.4 to 4.8 fold (ferrous oxidation) when stressed with $0.68 \mathrm{M}$ acid over 1 to 24 hours.

The effect of acid stress on microbial speciation was analysed by qPCR using nine species specific 16s rRNA primers as well as universal archaea and bacterial primers detailed in Table 2. A reduction in the diversity of the mixed microbial culture following acid stress was observed. In the inoculum, the culture was characterised as $90 \%$ L. ferriphilum, $5 \%$ A. cupricumulans, $3 \%$ F. acidiphilum and $1 \%$ At. ferrooxidans. An increase of the dominance of L. ferriphilum was observed to a high of $97 \%, 98 \%$ and $100 \%$ in the $0.34 \mathrm{M}, 0.51 \mathrm{M}$ and $0.68 \mathrm{M}$ stressed cultures respectively. The $F$. acidiphilum was gradually reduced from an initial $3 \%$ in the inoculum to $2 \%$ in the $0.34 \mathrm{M}$ and $0.54 \mathrm{M}$ stressed culture, then below detection limits of $1 \%$ in the $0.68 \mathrm{M}$ stressed culture, with A. cupricumulans and At. ferrooxidans being inhibited to below detection limits. A bioleach heap system requires both iron and sulphur oxidising micro-organisms to leach metal optimally. The iron oxidiser $L$. ferriphilum dominated this culture as typically reported for metal extraction operations conducted at temperatures of $40^{\circ} \mathrm{C}$ or less and rich in $\mathrm{Fe}^{2+}$ supply (Hallberg and Johnson, 2001; Coram and Rawlings, 2002). The iron and sulphur oxidiser At. ferrooxidans is able to 
operate autotrophically using sulphur and other reduced inorganic sulphur compounds as electron donors (Hallberg and Johnson, 2001). The observed dominance of L. ferriphilum can be attributed to its ability to scavenge low concentrations of $\mathrm{Fe}^{2+}$ and its preference for the temperature of the experiment, constantly maintained at $35^{\circ} \mathrm{C}$. In addition, the ability of L. ferriphilum to oxidise ferrous iron in a low solution $\mathrm{pH}$ range $(0.5-3.5)$ has been established previously (Plumb et al., 2008).

\section{Discussion}

In heap bioleaching, rapid microbial adaptation, attachment and onset of metabolic activity are factors that enhance metal recovery through the effective generation of the requisite leach agents, $\mathrm{H}^{+}$and $\mathrm{Fe}^{3+}$ (Chiume et al., 2012; Africa et al., 2010, 2012). This study has shown that the acid stress to which the mixed mesophile cultures is subjected increased the lag time of the micro-organisms before onset of microbial activity. This increased with both increasing acid concentration and time of exposure. Further, the time to attain maximum microbial count was delayed as acid stress increased, with a concomitant delay in the onset of bioleaching activity for the metal release.

The microbial community is responsible for the continual re-generation of the leach agents for leaching of the metal from the mineral in a heap bioleach system. The increase in the delay of the onset of metabolic activity in the stressed culture with increased acid stress, achieved in terms of acid concentration or exposure time, indicated that the conditions selected for agglomeration of mineral ore in the preparation stages of heap construction may influence the onset of microbial activity. This is particularly important where the heap is inoculated through agglomeration as the time of exposure to acid stress may be substantial. Heaps are constructed over an extended time with irrigation commencing after construction. On inoculation through agglomeration, this in turn can prolong the time micro-organisms are left exposed to extreme conditions before irrigation. Where the concentrations of acid used in 
the agglomeration processes are high, the recovery and initiation of metal leaching may be delayed extensively. Attention is drawn to the interaction between acidity and time of exposure: if the selected acid concentration of agglomeration is high, the negative acid stress resulting may be reduced by minimising the time between inoculation and commencement of irrigation.

\section{Conclusions}

The exposure of the mesophilic microbial culture to extreme acid conditions, approximating the acid environment experienced during acid agglomeration of the ore, demonstrated a negative effect on the onset of leaching. Most notably the time required to initiate microbial metabolism, both growth and ferrous iron oxidation, was extended relative to the control by a factor of two to five fold when returned to optimal operating conditions. The recovery times varied as a function of acid concentration and exposure time.

A lag time of 40 to 50 hours before the onset of bacterial iron oxidation was observed in the control. Following acid stress, these lag periods were increased to between 90 and $160 \mathrm{~h}, 103$ and $194 \mathrm{~h}$ and 138 and $260 \mathrm{~h}$ when cultures were exposed to $0.38 \mathrm{M}, 0.51 \mathrm{M}$ and $0.68 \mathrm{M}$ sulphuric acid for one hour, three hours and 24 hours respectively. Reduced metabolic activity resulted while recovery from the stress took place.

On adaptation or recovery from the stress, little change was observed in the instantaneous specific growth rate or iron oxidation rate during exponential growth. However extent of metal leaching over a defined time period was reduced, thus extending the leach period. This was accompanied by a decrease in the microbial diversity of the mixed culture implicated in leaching, demonstrating the varying robustness with respect to acid stress. The major impact of the acid stress in a heap bioleaching operation will therefore be the time required for the onset of growth and metabolic activity of the leaching micro-organisms following their 
introduction into the operation. This impacts the time required for microbial colonisation of the heap, establishment of optimal generation of leach agents such that microbial oxidation is not rate limiting and, hence, the time required for metal recovery from the heap.

This represents the first direct study presented on the microbial response of micro-organisms implicated in bioleaching to acid stress and provides understanding with which to inform the start-up process in heap leaching. This study requires extension to consider the concomitant effect of ionic strength and metals in solution on microbial activity, owing to the rapid acid dissolution of gangue minerals during acid agglomeration and their accumulation in the ore bed prior to irrigation.

\section{Acknowledgements}

Financial support from the South African Research Chairs Initiative of the Department of Science and Technology and the National Research Foundation in South Africa are gratefully acknowledged. BHP-Billiton is acknowledged for the supply of the pyrite. The contributions of Marijke Fagan and Elaine Govender in the preparation of the manuscript is much appreciated.

\section{References}

Africa, C.J., Harrison, S.T.L., Becker, M., van Hille, R.P., (2010). In situ investigation and visualisation of microbial attachment and colonisation in a heap bioleach environment: the novel biofilm reactor. Minerals Engineering 23, 486 - 491.

Africa, CJ., van Hille, R.P., Harrison, S.T.L. (2012). Attachment of Acidithiobacillus ferrooxidans and Leptospirillum ferriphilum cultured under varying conditions to pyrite, chalcopyrite, low-grade ore and quartz in a packed column reactor. Applied Microbiology and Biotechnology 97, 1317 - 1324.

Bouffard, S.C. (2005). Review of agglomeration practice and fundamentals in heap leaching. Mineral Processing and Extractive Metallurgy Review, 26, 233 - 294. 
Brierley, J.A. (2008). A perspective on developments in biohydrometallurgy. Hydrometallurgy 94, $2-7$.

Coram, N.J., Rawlings, D.E. (2002). Molecular relationship between two groups of the genus Leptospirillum and the finding that Leptospirillum ferriphilum sp. no. dominates in South African commercial biooxidation tanks that operate at $40^{\circ} \mathrm{C}$. Applied Environmental Microbiology, 68, 838-845.

Chiume, R., Minnaar, S.H., Ngoma, I.E., Bryan, C.G., Harrison, S.T.L. (2012). Microbial colonization in heaps for mineral bioleaching and the influence of irrigation rate. Minerals Engineering 39, 156 - 164.

Deveci H., Jordan M.A., Powell N. and Alp I. (2008). Effect of salinity and acidity on bioleaching activity of mesophilic and extremely thermophilic bacteria. Trans. Nonferrous Met. Soc. China, 18, $714-721$.

Dhawan, N., Safarzadeh, M.S., Miller, J.D., Moats, M.S., Rajamani, R.K. (2013). Crushed ore agglomeration and its control for heap leach operations. Minerals Engineering 41, 53 70 .

Dhawan, N., Safarzadeh, M.S., Miller, J.D., Rajamani, R.K., Moats, M. (2012). Insights into heap leaching Technology. SME Annual Meeting - Feb 19 - 22, 2012, Seattle, Washington. Preprint $12-119$.

Hallberg, K.B., Johnson, D.B. (2001). Biodiversity of acidophilic prokaryotes. Advances in Applied Microbiology, 49, 37-84.

Kappes, D.W. (2005). Heap leaching of gold and silver ores. Advances in gold ore processing, Vol 15. Development in Mineral Processing, Chapter 19, 456 - 478.

Kodali, P., Depci, T., Dhawan, N., Wang, X., Lin, C.L., Miller, J.D. (2011). Evaluation of stucco binder for agglomeration in the heap leaching of copper ore. Minerals Engineering, 24(11), $886-893$.

Komadel, P., Stucki, J.W. (1988). Quantitative assay of minerals for $\mathrm{Fe}^{2+}$ and $\mathrm{Fe}^{3+}$ using 1,10 phenantroline: III. A rapid photochemical method. Clays and Clay Minerals, 36(4), 379 381.

Nemati, M., Harrison, S.T.L. (2000). Effect of solid loading on thermophilic bioleaching of sulphide minerals. Journal of Chemical Technology and Biotechnology, 75, 526 - 532.

Norris, P.R., Clark, D.A., Owen, J.P., Waterhouse, S. (1996). Characteristics of Sulfobacillus acidophilus sp. nov. and other moderately thermophilic mineral-sulphide-oxidising bacteria. Microbiology 142, 775 - 783.

Plumb J.J., Muddle R. and Franzmann P.D. (2008). Effect of pH on rates of iron and sulphur oxidation by bioleaching organisms. Minerals Engineering 21, 76 - 82. 
Purkiss, S., Anthony, R. (2004). Heap leaching base metals from oxide ores. International Publication. No. WO 2004/031422 A1. International Publication Date. 15 April 2004.

Schlitt, W.J. (1992). Solution mining: surface techniques. In: SME Mining Engineering Handbook, Hartman, H.I. (ed). 15(2), 1478 - 1492.

Song J., Franzmann P.D., Lin J. and Kaksonen A.H. (2011). Respirometry studies of bioleaching of low-grade chalcopyrite ore using six acidophilic strains. Minerals Engineering $24,1139-1145$.

Song J., Gao L., Lin J., Wu H., and Lin J. (2013). Kinetics and modelling of chemical leaching of sphalerite concentrate using ferric iron in a redox-controlled reactor. Chinese Journal of Chemical Engineering 21(8), 933-936.

Tupikina O, Ngoma E., Minnaar S and Harrison S T L. (2011). Some aspects of pH effects and acid stress in heap leaching. Minerals Engineering 24 (11), 1209 - 1214.

Tupikina, O.V., Minnaar, S.H., van Hille, R.P., van Wyk, N., Rautenbach, G.F., Dew, D., Harrison, S.T.L. (2013). Determining the effect of acid stress on the persistence and growth of thermophilic microbial species after mesophilic colonisation of low grade ore in a heap leach environment. Minerals Engineering 53, 152 - 159

Watling, H.R. (2006). The bioleaching of sulphide minerals with emphasisi on copper sulphides - A review. Hydrometallurgy 84, 81 - 108. 